\title{
A COMPARISON OF THE TENSILE AND BENDING PROPERTIES OF DENTAL GOLD WIRES
}

\author{
D. F. TAYLOR, M.S.E., ${ }^{*}$ AND F. A. PEYTON, D.Sc. \\ School of Dentistry, University of Michigan, Ann Arbor, Mich.
}

\section{INTRODUCTION}

$\mathrm{M}$ ODERN dental practice makes wide use of precious metal alloys in wire form as partial denture clasps and as orthodontic appliances. When used in such applications, these alloys are subject only to bend loading and never to pure tensile loading. For this reason, there has long been a feeling within the dental profession that the tensile test for wires was somewhat inappropriate and might be replaced advantageously by a bend test. However, the absence of any previous correlation between the test values obtained from the two types of loading, as well as the large amount of effort represented by collected tensile data on these alloys, has heretofore prevented any serious consideration of a possible change of standards from one test to the other. The technical representatives of several manufacturers have displayed a continuing interest in the development of possible relationships between tension and bend tests. This interest was expressed through the loan, by these manufacturers, of gold alloy wires of high intrinsic value for use in this investigation. Further support was received from the Office of Naval Research which sponsored the project as a part of its program of research on the properties of restorative dental materials.

The specific purpose of this investigation was to determine what correlation, if any, existed between the mechanical properties of wrought gold alloys as found in a standard tensile test and those as found in a bend test. The type of bend test used in this investigation was the cantilever loading of a wrought gold wire. It is believed that the conditions of such a bend test much more nearly approach the actual conditions under which these alloys are used than does the tensile test.

The program of the project was set up as follows: An attempt was made to obtain a wide range of inherent mechanical properties in the alloys to be tested, at the same time reducing as far as possible other variables such as wire size, sample length, and heat treatment. A total of twelve alloys was selected, all of the same size and all to be subjected to identical heat treatment and testing. These alloys were to be tested in two conditions, fully soft (10 min. at $700^{\circ}$ C., quench), and age hardened (softened as above, then $15 \mathrm{~min}$. at $360^{\circ} \mathrm{C}$.). It was recognized that this hardening practice might not produce either the maximum or optimum properties of any one alloy, but it was

These studies were aided by a contract between the Office of Naval Research, Department of the Navy, and the University of Michigan, N6-onr-232, Task Order VIII (NR 181-360). Received for publication, Sept. 19, 1950.

*Present address: Washington University School of Dentistry, St. Louis, Mo. 
employed to eliminate possible variation resulting from differing heat treatments, and because it could be controlled more accurately than oven cooling. For each alloy in each condition three tensile tests and three bend tests were planned. It was proposed that stress-strain curves be taken for each specimen and the properties of the wires calculated from the curves. The desired comparison of the two tests was to be obtained from the average values of the three specimens of each type. This method was followed as closely as possible and in general the results obtained were quite satisfactory.

A separate investigation is being made of the microstructures of these alloys and will be reported separately.* In this study no immediate attempt was made to correlate the results of the mechanical tests with the microstructure of the alloys. The equilibrium relationships for the alloys used are complex, since all of the alloys have five or more components present to the extent of 0.5 per cent or more, and some alloys may contain as many as seven major components and traces of others. Considering the complexity of the dental gold alloy system, only a relatively small amount of study has been devoted to the investigation of its properties. The binary systems are known ${ }^{1}$ and some work has been done on ternaries, but of the more complex systems only portions of two pseudobinaries, in the platinum-gold-silver-copper and palladium-gold-silver-copper quartenary systems are available. ${ }^{2,3}$

\section{METHOD OF INVESTIGATION}

Three alloys from each of four well-known manufacturers were selected for the test. The selection was made on the basis of data available in manufacturers' physical property charts. An attempt was made to select alloys that would give a fairly ever distribution of values over the entire range of tensile properties and at the same time to select one inherently soft, medium, and hard alloy from each manufacturer. The nominal chemical compositions of the alloys selected are given in Table I.

These alloys were received as 1 -foot lengths of $0.040 \mathrm{in}$. wire, which were cut into 6-inch lengths for heat treatment. A bundle of 6-inch wires was bound together with stainless steel ligature wire and suspended in a vertical muffle

TABLE I

Nominal Compositions

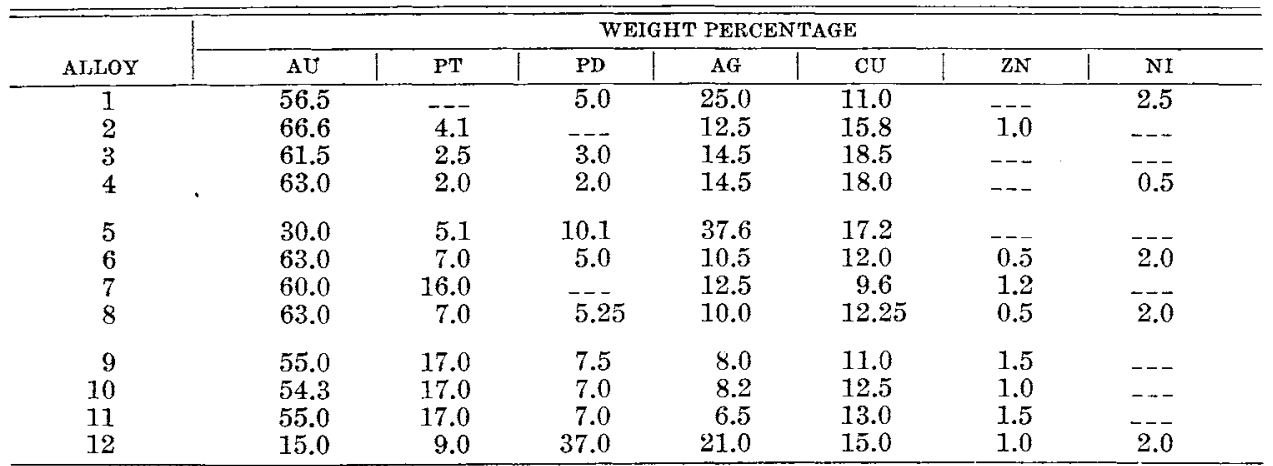

*J. Pros. Dent. 1: 177, 1951. 
electric resistance furnace. A chromel-Alumel thermocouple was inserted into the middle of the bundle, and a Leeds and Northrup semi-precision potentiometer was used to measure the temperature of the wires.

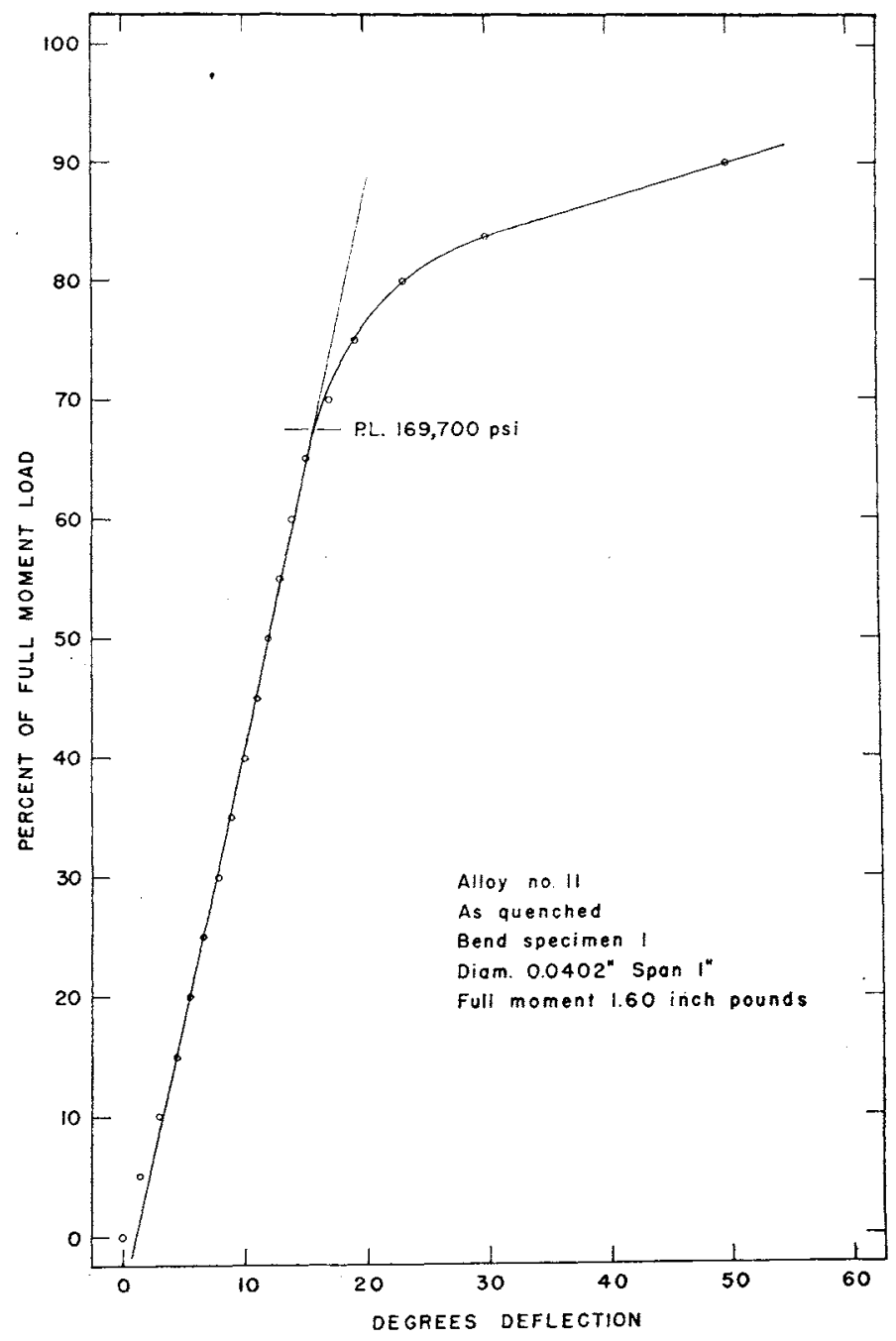

Fig. 1.-Typical bend curve.

The heat treatment used was as follows: The bundle of wires was inserted into a furnace preheated to $700^{\circ} \mathrm{C}$, and held there for 10 minutes, reaching furnace temperature within 2 to 3 minutes. After 10 minutes in the furnace, the bundle of wires was quenched in room temperature water. This treatment corresponds to the American Dental Association specification No. 7 recommended softening treatment. For those specimens to be tested in the hardened condition, this softening treatment was followed by aging in a salt bath for 15 minutes at $360^{\circ} \mathrm{C}$. and water quenching to room temperature. 
Three wires from each bundle were selected for tensile testing and one for bend testing. The wire to be used in the bend test was cut into three 2-inch lengths which were sufficient for that purpose. The instrument used was a Tinius Olsen stiffness tester of five inch-pounds' bending moment capacity, similar to the instrument described by Shell. ${ }^{4}$ For this investigation, the moment arm was fixed at 1 inch while the weights were varied to fit the anticipated properties of the materials. Load increments of 5 per cent of the full moment load were used, with additional points being taken after yielding started.

The tensile specimens were tested in a Tinius Olsen tensile testing machine of 1,000 pounds' total capacity. It was of the mechanical drive type, equipped with an auxiliary motor that gave a head travel of 0.024 inch per minute. Loading was stopped while readings were taken; the resulting effective loading rate was approximately 20,000 pounds per square inch (psi) per minute. Readings were taken at 5-pound intervals and the strain was read to the nearest 0.0001 inch. The gauges used were of the type developed at the National Bureau of Standards for this purpose. ${ }^{5}$ They are made in matched pairs mounting on opposite sides of the wire. They thus avoid eccentrically loading the wire because of uneven distribution of gauge weight. This mounting also compensates for small bends left in the wire by previous treatments, the average of the two dials being a good average strain for the whole cross section. To minimize further the effect of erooked wires, initial readings were taken at a 5 -pound load.

Using this method, and with assistance in reading the second tensile gauge, three bend and three tensile specimens were tested for each alloy in both the hard and soft condition. Two additional series of tests were made in the soft condition with the result that twenty-six average tensile values and corresponding bend ralues were obtained.

\section{EXPERIMENTAL RESULTS}

In Figs. 1 and 2 are plotted the typical results for bend and tensile tests. Both curves represent the data for Alloy 11. Results from other alloys give comparable curves. These curves were plotted in terms of the measured units (i.e., load and strain or deflection), and the stress values were calculated after the proportional limit and modulus were determined on the graph of each specimen. The proportional limit was taken as that point where the best curve through the points visibly deviated from a straight line. This differs slightly from the value normally reported for these alloys, ${ }^{6}$ which is determined as the point at which the slope of the eurve is 1.25 times the elastic slope. The absolute difference is in most cases very small, as most of the alloys tested tend to elongate very rapidly once the proportional limit is reached. The method used in this project was selected because it was independent of the plastic strain rate, and because the formulae used for calculating stresses in the bend tests apply only within the truly elastic range of the material. Tables II and III report a summary of the experimental data on proportional limit, ultimate tensile strength, and modulus of elasticity. 
TABIE II

Mechanical Properties

\begin{tabular}{|c|c|c|c|}
\hline \multirow[b]{2}{*}{ ALLOY } & \multicolumn{2}{|c|}{ PROPORTIONAL LIMITS } & \multirow{2}{*}{$\begin{array}{c}\text { ULTIMATE TENSILE } \\
\text { STRENGTHS } \\
\text { EXPERIMENTAL } \\
\text { PSI }\end{array}$} \\
\hline & $\begin{array}{c}\text { BENDING } \\
\text { EXPERIMENTAL } \\
\text { PSI }\end{array}$ & $\begin{array}{c}\text { TENSION } \\
\text { EXPERIMENTAL } \\
\text { PSI }\end{array}$ & \\
\hline 1 & 83,600 & 51,700 & 90,700 \\
\hline $1 a$ & 76,500 & 51,500 & 92,300 \\
\hline 2 & 71,700 & 49,450 & 75,200 \\
\hline 3 & 78,600 & 49,700 & 81,200 \\
\hline 4 & 83,500 & 55,000 & 86,700 \\
\hline 5 & 97,100 & 58,000 & 87,500 \\
\hline 6 & 127,000 & 67,000 & 107,300 \\
\hline $6 a$ & 119,600 & 69,200 & 110,500 \\
\hline 7 & 113,900 & 65,700 & 100,800 \\
\hline 8 & 129,700 & 87,000 & 115,800 \\
\hline 9 & 122,900 & 66,900 & 108,200 \\
\hline 10 & 145,400 & 72,400 & 114,800 \\
\hline 11 & 167,500 & 95,250 & 130,800 \\
\hline 12 & 129,800 & 79,800 & 126,000 \\
\hline $1 h^{*}$ & 189,500 & 97,800 & 140,500 \\
\hline $2 \mathrm{~h}$ & 146,300 & 84,870 & 112,700 \\
\hline $3 h$ & 168,200 & 92,500 & 129,200 \\
\hline $4 h$ & 169,530 & 101,430 & 130,700 \\
\hline $5 \mathrm{~h}$ & 140,000 & 89,300 & 115,200 \\
\hline $6 h$ & 211,100 & 129,370 & 163,800 \\
\hline $7 \mathrm{~h}$ & 162,700 & 94,800 & 128,500 \\
\hline $8 \mathrm{~h}$ & 198,530 & 128,230 & 152,800 \\
\hline $9 \mathrm{~h}$ & 162,200 & 100,730 & 135,700 \\
\hline $10 \mathrm{~h}$ & 178,130 & 107,700 & 135,700 \\
\hline $11 \mathrm{~h}$ & 215,400 & 129,600 & 167,800 \\
\hline \multirow[t]{2}{*}{$12 \mathrm{~h}$} & 174,300 & 107,830 & 142,200 \\
\hline & \multicolumn{2}{|c|}{ Independent Data } & - \\
\hline A & 95,000 & 61,000 & \\
\hline $\mathrm{B}$ & 113,000 & 67,500 & \\
\hline $\mathrm{C}$ & 94,700 & 53,000 & \\
\hline $\mathrm{D}$ & 84,800 & 60,300 & \\
\hline $\mathrm{E}$ & 130,000 & 74,000 & \\
\hline
\end{tabular}

${ }^{*} \mathrm{~h}$ denotes hardened condition.

In Fig. 3 is plotted the experimentally determined proportional limit in bending versus the log of the proportional limit in tension, as reported in Table II. Also shown are five points as determined independently by another investigator $^{7}$ on wires of similar size and composition. It will be noted that, on this type of plot, the data can be represented by a straight line. The equation of this line, excluding the independent points, was found by the method of least squares to be $\log \mathrm{P}_{\mathrm{T}}=3.004 \times 10^{-6} \mathrm{P}_{\mathrm{B}}+4.478$.

An attempt was made to account for the deviation of various points from this line. It was found to be impossible to do so, however, with respect to any of the variables upon which data were available. The variable which might be expected to have the most effect, wire diameter, was kept within quite narrow limits. The nominal size of all of the wires used was 0.040 inch; the actual diameter of the specimens after heat treatment ranged from 0.0396 to 0.0405 inch. Over this range the effect of size, if any, was concealed by individual variations between alloys. 
TABLE III

Modulus of Elasticity

\begin{tabular}{c|cc}
\hline \hline & $\begin{array}{c}\text { BENDING } \\
\text { EXPERIMENTAL } \\
10^{6} \text { PSI }\end{array}$ & $\begin{array}{c}\text { TENSION } \\
\text { EXPERIMENTAL } \\
106 \text { PSI }\end{array}$ \\
\hline 1 & 12.523 & 12.050 \\
$1 \mathrm{a}$ & 12.250 & 11.330 \\
2 & 11.102 & 11.172 \\
3 & 11.883 & 12.217 \\
4 & 12.187 & 11.020 \\
5 & 11.990 & 11.030 \\
6 & 14.300 & 13.330 \\
$6 \mathrm{a}$ & 13.530 & 12.970 \\
7 & 13.273 & 11.990 \\
8 & 15.157 & 12.967 \\
9 & 13.880 & 14.420 \\
10 & 14.817 & 14.283 \\
11 & 16.217 & 14.490 \\
12 & 17.097 & 18.017 \\
$1 \mathrm{~h}$ & 14.950 & 13.073 \\
$2 \mathrm{~h}$ & 13.513 & 11.703 \\
$3 \mathrm{~h}$ & 14.910 & 13.090 \\
$4 \mathrm{~h}$ & 14.473 & 12.210 \\
$5 \mathrm{~h}$ & 13.160 & 13.300 \\
$6 \mathrm{~h}$ & 17.127 & 14.327 \\
$7 \mathrm{~h}$ & 14.663 & 12.883 \\
$8 \mathrm{~h}$ & 16.393 & 13.699 \\
$9 \mathrm{~h}$ & 16.030 & 14.833 \\
$10 \mathrm{~h}$ & 18.013 & 15.173 \\
$11 \mathrm{~h}$ & 17.483 & 15.157 \\
$12 \mathrm{~h}$ & 19.217 & 17.867 \\
\hline
\end{tabular}

The values obtained for modulus in bending and in tension are plotted against each other in Fig. 4. This plot exhibits much more scatter than appeared in that of the proportional limits. While the general relationship between the two tests is fairly apparent, it is confused by the deviation of individual alloys from the mean. As a mechanism to determine this trend somewhat more accurately, a plot was made (Fig. 5) of the change of modulus in tension versus the change of modulus in bending for each alloy between the soft and hardened conditions (see Table IV). From this figure it can be seen that, in general, the effect of any aging heat treatment is to increase the modulus both in bending and in tension. The increase of the bending values is greater than that of the tensile values. The only two points that violate these general rules are those of the two alloys that do not fall within the normal composition range for these alloys. One alloy (alloy 5 ) has silver for its main component, and the other (alloy 12) has palladium as a base (see Table I). Modulus values as determined in this investigation seem to be more subject to the influence of variables which could not be controlled than are the values obtained for proportional limit. The method by which they were determined, drawing by eye the best straight line through the plotted points, is admittedly subject to error. The adoption of a more precise method, a differential curve perhaps, did not seem justified in what was essentially an extensive rather than an intensive investigation. 


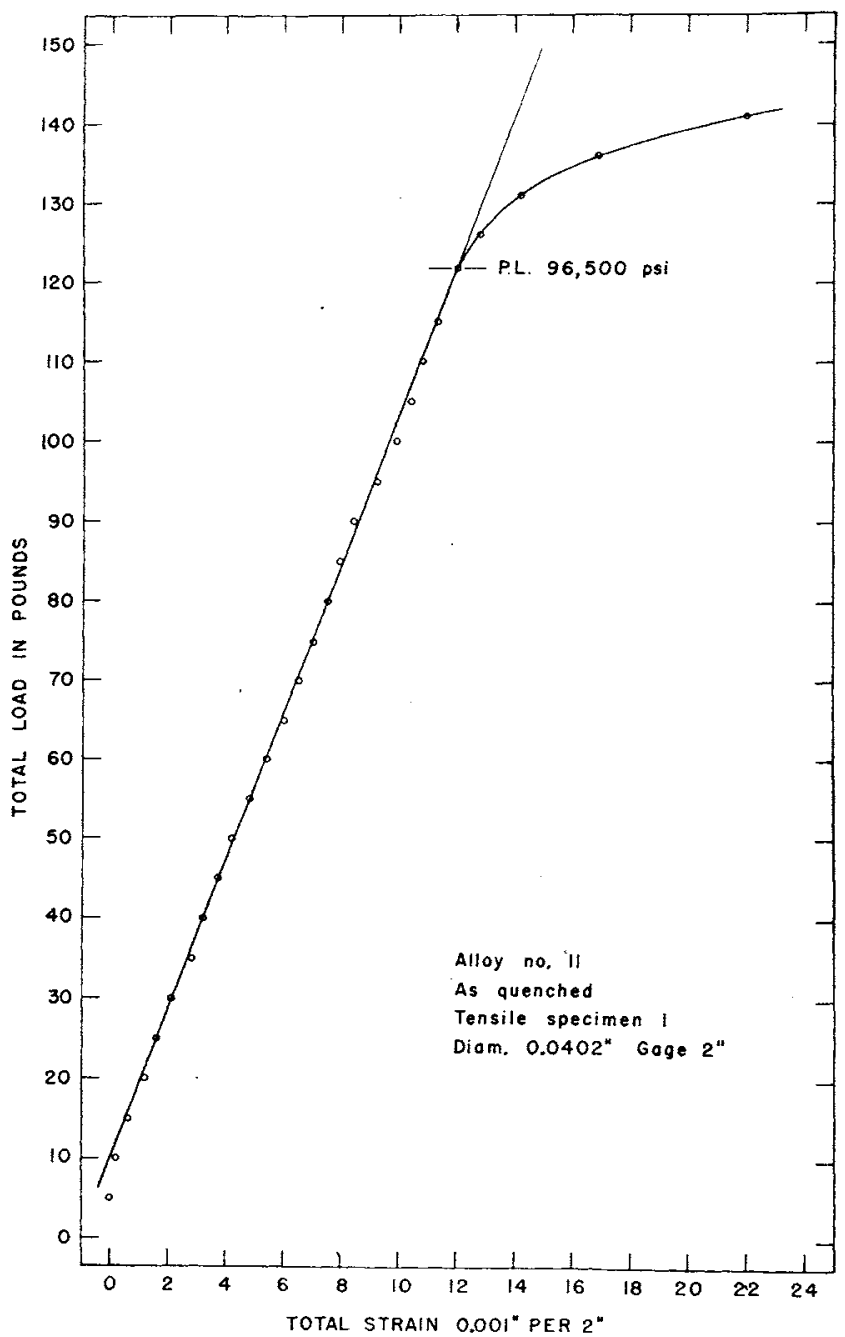

Fig. 2.-Typical tensile curve.

TABLE IV

Change in Modulus on Heat Treatment

\begin{tabular}{c|c|c}
\hline ALLOY & MODULUS TENSION & MODULUS BENDING \\
\hline 1 & $1,023,000$ & $2,420,000$ \\
la & $1,743,000$ & $2,700,000$ \\
2 & 531,000 & $2,411,000$ \\
3 & 873,000 & $3,027,000$ \\
4 & $1,180,000$ & $2,286,000$ \\
5 & $2,270,000$ & $1,170,000$ \\
6 & 997,000 & $2,827,000$ \\
$6 \mathrm{a}$ & $1,357,000$ & $3,597,000$ \\
7 & 893,000 & $\mathbf{1 , 3 9 0 , 0 0 0}$ \\
8 & 732,000 & $\mathbf{1 , 2 4 0 , 0 0 0}$ \\
9 & 463,000 & $2,150,000$ \\
10 & 890,000 & $3,196,000$ \\
11 & 661,000 & $\mathbf{1 , 2 6 6 , 0 0 0}$ \\
12 & $-150,000$ & $2,120,000$ \\
\hline
\end{tabular}




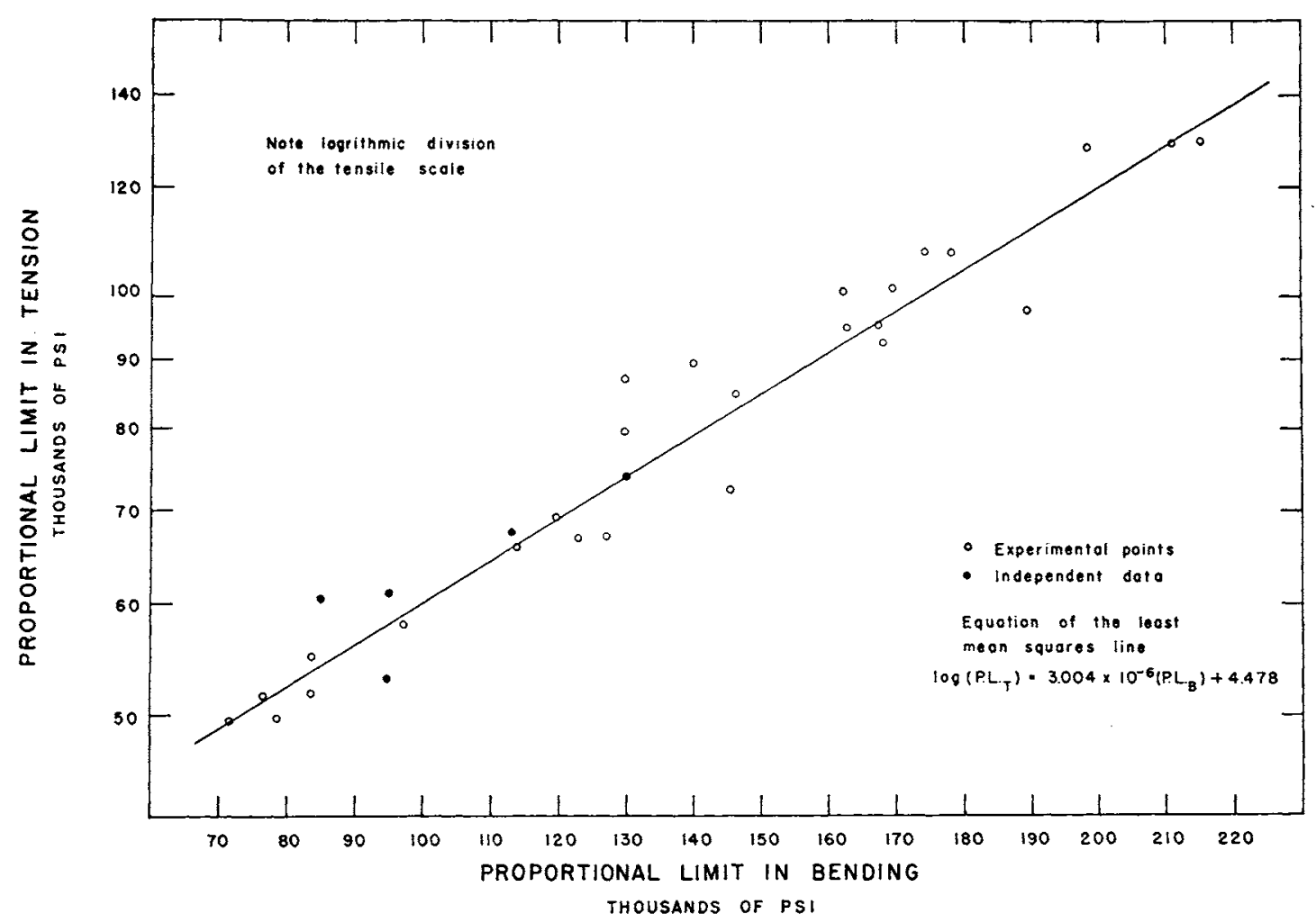

Fig. 3.-Proportional limits, bending vs. tension.

The method used seems to have been in general well suited to the scope and purpose of the project. The limited number of specimens tested for each condition precluded any weighing or statistical treatment of the data, yet for the proportional limit data the average probable error for the individual points is 2.58 per cent in tension and 2.18 per cent in bending. The probable error for an individual reading with respect to the least mean squares curve is only 4.76 per cent for the experimental data taken. If Alloys $A$ to $\mathrm{E}$ from Table II are included, the probable error is 4.65 per cent.

The equipment used was checked for accuracy as far as possible. The stiffness tester consists essentially of two moment arms and a set of weights. These were measured and found to be correct. The tensile machine was checked against a standard test ring and compared with another machine of the University of Michigan Engineering Mechanics Department, which was known to be accurate. As a final check, two unidentified specimens of each of three alloys were sent to another laboratory for tensile tests. The results show good agreement with the values obtained in this investigation. These results are compared in Table $V$. 


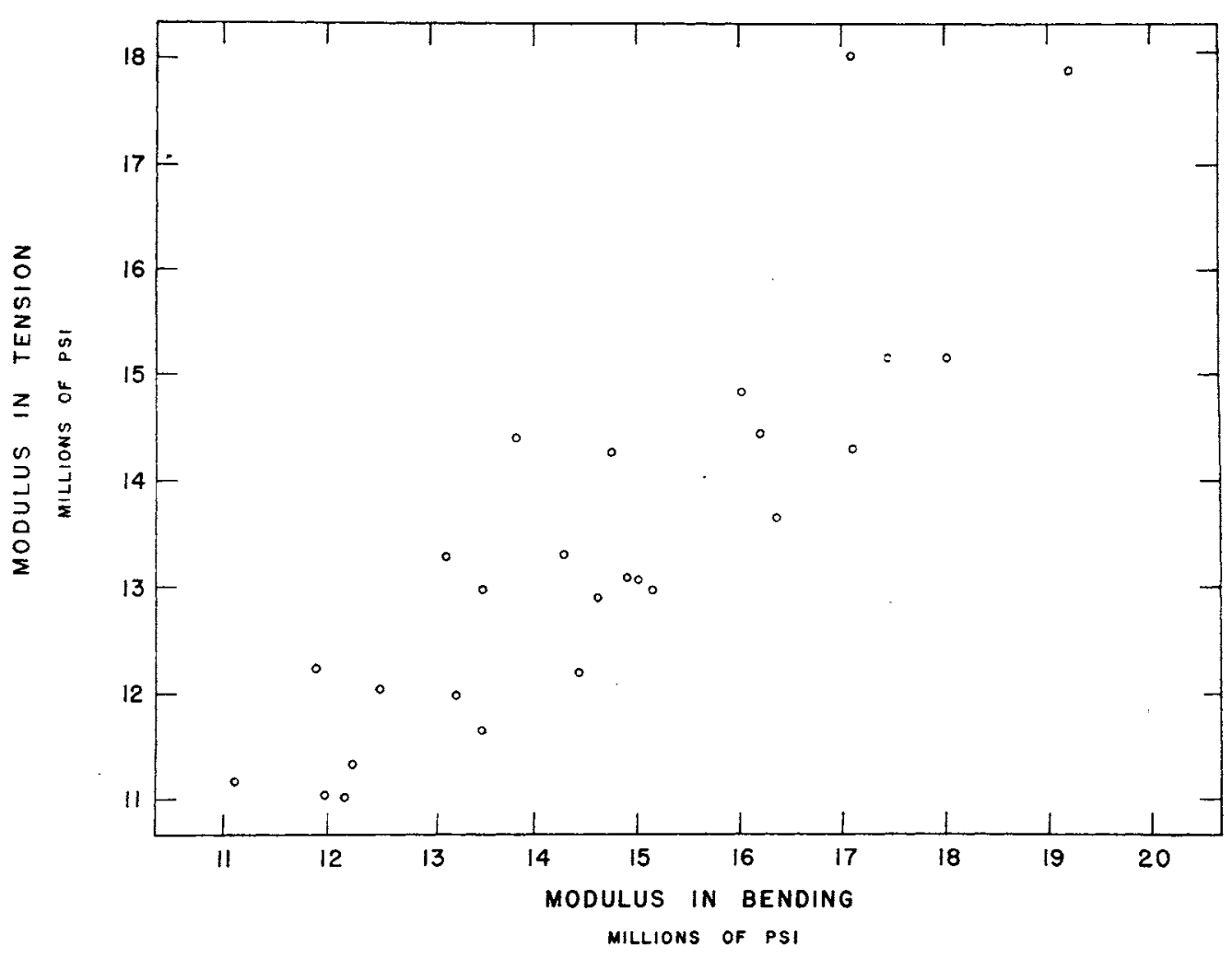

Fig. 4.-Moduli of elasticity, bending vs. tension.

TABLE $\mathrm{V}$

Check on Tenstle Resulas

\begin{tabular}{r|cr|r|r}
\hline & \multicolumn{2}{|c}{ ULTIMATE TENSILE STRENGTH } & \multicolumn{2}{c}{ PROPORTIONAL LIMIT } \\
\cline { 2 - 5 } ALLOY & TEST VALUES & $\begin{array}{c}\text { INDEPENDENT LAB- } \\
\text { ORATORY VALUES }\end{array}$ & TEST VALUES & $\begin{array}{c}\text { INDEPENDENT LAB- } \\
\text { ORATORY VALURS }\end{array}$ \\
\hline $8 \mathrm{~h} 1$ & $\mathbf{1 5 2 , 8 0 0}$ & 158,000 & 128,230 & 126,500 \\
$8 \mathrm{~h} 2$ & 152,800 & 158,000 & 128,230 & 126,500 \\
$9 \mathrm{~h} 1$ & 135,700 & 135,000 & 100,730 & 90,000 \\
$9 \mathrm{~h} 2$ & 135,700 & 135,000 & 100,730 & 93,800 \\
$10 \mathrm{~h} 1$ & 135,700 & 136,500 & 107,700 & 101,000 \\
$10 \mathrm{~h} 2$ & 135,700 & 133,000 & 107,700 & 101,000 \\
\hline
\end{tabular}

\section{ANALYSIS OF RESULTS}

Every method of physical testing to determine the properties of a material involves some inherent assumptions. In the case of the tensile test, the primary assumptions are few and deviate so little from actuality for most materials that they introduce very little error in the calculated properties. The two main assumptions are that the area of the cross section remains constant. Within the elastic range these assumptions are reasonably exact, and the only property involving them that is taken from the plastic range is the ultimate tensile strength. This value is always calculated on the original area for design purposes, and 


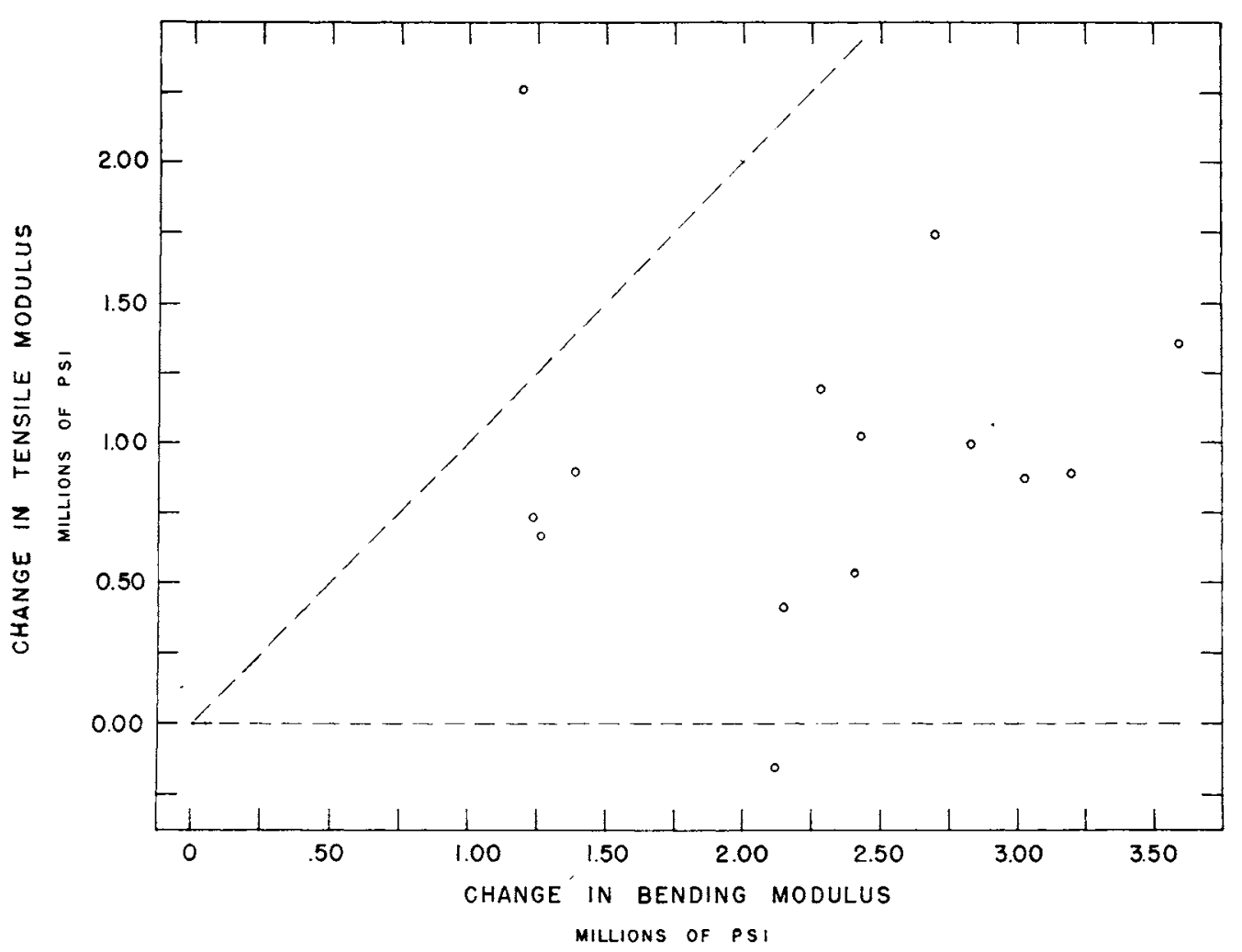

Fig. 5.-Change in moduli, bending vs. tension.

actually represents the stress at which the cross-sectional area is decreasing faster than the material is work hardening, rather than the maximum stress the material will bear.

The assumptions involved in a bend test are more complex and tend to introduce a larger deviation from the true properties of the material than those in the tensile test. In calculating the properties in a cantilever bend test, it is assumed that the behavior of the material is truly elastic up to the observed proportional limit, that the neutral axis of the wire does not shift during loading, and that the material has identical properties in tension and compression. It is also assumed that the stresses, deformation, and cold work introduced by the elamping process can be neglected.

Current theory states that if sufficient data are available to calculate the errors introduced by the failure of the above assumptions to hold true, the properties of a material in bending and in tension will be found to be equal. The fact that the values obtained from using the two tests are not the same indicates that some or all of the assumptions made for the bend specimens are inexact. This, however, does not of itself invalidate the bend test, but rather supports it, in that it demonstrates the inapplicability of data derived in one situation for use in the other. 
It is at present impossible to design a dental appliance rigorously from tensile data. To do so would require unavailable data on the compressive properties, the shift of the neutral axis, and the effect of end conditions for dental alloys subjected to bending. However, it would be possible to design an appliance from data derived from a bend test. The total effect of all the undetermined deviations from ideality has been included in the data by using a test situation similar to the desired application.

In practice, dental appliances are never designed from the basic mechanical data. The properties reported in physical property eharts are used mainly as a basis for the comparison and selection of alloys. For this purpose, bend test data are equally as satisfactory and offer the added advantage of having been derived from a situation as nearly the same as the intended use as is possible.

In selecting the alloys for use in this investigation, no attempt was made to choose them on the basis of composition. As a result, a wide range of composition is represented in the alloys tested. Similarly, during testing no special effort was made to insure uniform clamping conditions. Yet, in spite of these two factors, the random variation of which would be expected to increase the scatter in the data, a close correlation was obtained between the two test methods (Fig. 3). From this it can be anticipated that using uniform clamping conditions for the bend test will result in an improved correlation between the two tests, and that a single curve will suffice for the entire composition range of wrought dental gold alloys.

SUMMARY

An investigation was made of the relative values of the mechanical properties of precious metal wires in tension and in bending. The properties determined were modulus of elasticity and proportional limit in bending, and modulus of elasticity, proportional limit, and ultimate strength in tension.

A series of alloys in the form of 0.040 inch diameter wires was tested by means of a standard tensile test, and by a cantilever loading bend test. Each alloy was tested, first in the solution treated (soft), and second in the solution treated and aged (hard) conditions. The final values recorded for each alloy condition were the arithmetic averages of the data from three tensile specimens and three bend specimens. To obtain these individual values, stress-strain curves were plotted for each specimen, and the apparent proportional limit and modulus were determined from each curve.

The values found for proportional limit ranged from 50,000 psi to 130,000 psi in tension and from 70,000 psi to 215,000 psi in bending. A definite correlation between the results of the two tests was found. When plotted on semi$\log$ paper it yields a straight line having an empirieal equation of the form $\log _{10} P_{x^{i}}-a P_{B}+b(1)$ where $a$ and $b$ are constants, $P_{T}$ is the proportional limit in tension and $P_{B}$ is the proportional limit in bending. a was found to be $3.004 \times 10^{-6}$, and $\mathrm{b}$ was found to be 4.478 . 
Earlier data by another investigator for similar alloys on specimens of the same size fit this curve very well. The average probable error of conversion from bend values to tensile values for the data of this investigation is 4.76 per cent; including the independent points it is 4.65 per cent. The alloys tested (covering the normal range of composition for wrought dental alloys) fit this single correlation in spite of varying clamping conditions in the bend test. The use of standard clamping conditions can be expected to yield an improved correlation unaffected by normal differences in alloy composition.

The results for modulus were more widely scattered but certain trends can be noted. A wide range of values was found for modulus in both tests. Tensile values ranged from $11 \times 10^{6}$ psi to $18 \times 10^{6} \mathrm{psi}$, while bend values ranged from $11 \times 10^{6}$ psi to $19 \times 10^{6}$ psi. As far as is known, this is a greater range than has previously been reported.

For most alloys and heat treatments, the modulus in bending is greater than that in tension. The effect of aging was to increase the modulus, both in bending and in tension, as the proportional limit was raised. An aging heat treatment increased the modulus, as found in bending, more than that found in tension.

Work is being continued on this project with the intention of extending it to a greater scope. It is believed that this comparison of tensile and bend properties of wires may be valuable, not only to the dental profession, but the correlation between tension and bending properties may be useful to those in industry where wires are employed.

The authors wish to acknowledge the cooperation of the Handy and Harman (Dee) Company, the J. M. Ney Company, the Spyco Smelting \& Refining Co., and The S. S. White Dental Mfg. Co., and their assistance in providing wire for this study.

\section{REFERENCES}

1. A.S.M. Metals Handbook, 1948, p. 1148 ff.

2. Crowell, W. S., Wise, E. M., and Eash, J. T.: Institute of Metals Division, A.I.M.E. 99: 363,1932 .

3. Wise, E. M., and Eash, J. T.: Institute of Metals Division, A.I.M.E. 104: 276, 1933.

4. Shell, J. S.: 'J. A. D. A. 27: 232, 1940.

5. Taylor, N. O., Paffenbarger, G. C., and Sweeney, W. T.: J. A. D. A. 19: 413, 1932.

6. Crowell, W. S.: J. A. D. A. 19: 87, 1932.

7. Unpublished data communicated by R. C. Brumfield, J. F. Jelenko \& Co., Inc.

\section{ERRATUM}

The article by Koser and Fisher, "Vitamin Requirements of Oral Lactobacilli," $J$. D. Res. 29: $760-773$, 1950, contains a table in which broken type resulted in erroneous data. In Table III, p. 768, the last column (Thiamine) should have plus signs opposite Cultures $78,1002,1013$, and 1015 , in addition to those which are clear. 